\section{REPORT ON "THE SECOND INTERNATIONAL CONGRESS IN ISRAEL ON DISASTER MANAGEMENT": JERUSALEM, SEPTEMBER 17th and 18th, 1984}

Maj H G Bosanquet, $M B, C h B, R A M C$

I attended the conference as a military psychiatrist, in order to learn how different nations, especially Israel, manage disasters, both man-made, such as terrorist attacks, and natural, such as earthquakes and fires.

The conference was organized by the three chief Israeli University Hospitals, the Israel Medical Association, and the World Association for Emergency and Disaster Medicine. It was divided into fifteen 'workshops', the majority running for half a day in parallel. During each workshop, an average of eight papers, each for 20 minutes, were presented. Of the total of 120 papers, 50 were from Israeli contributors, 25 from US, 10 from Sweden and seven from the UK. The workshops were organized under five main themes:

1. Organization of Emergency Services and Hospital Planning -3 workshops.

2. National Organization for Disasters -5 workshops.

3. Emergency Medical Treatment -4 workshops.

4. Education and Training -2 workshops.

5. Psychological Aspects of Disasters - 1 workshop.

I attended the first workshop on Organization of Emergency Services, "Socio-Economic Aspects of Disasters", "Psychological Aspects of Disasters" and the all-day workshop "Education and Training for Disaster Situations".

"Socio-Economic Aspects of Disasters" was chiefly useful for two Israeli papers, "Hospital Disaster Plan Attention to Social and Personal Problems of Casualties and Relatives", and "Helping a Community to cope with a systematic threat - a Social Service View".

The first of these was a description of the non-medical parts of the Hospital Disaster Plan of the Hedassah Hospital, the chief hospital in Jerusalem. The plan has been in use for 12 years, and has frequently been needed, mainly after terrorist bomb explosions, and large scale road accidents. The plan is unusual in its emphasis on the psychological effects of disasters on victims and their families, to help them cope with both the immediate and long term stress. The immediate stress is alleviated by ensuring that they are not given contradictory, exaggerated or obscure information about injuries, a real danger is the often confused period immediately after a victim's arrival in hospital. Special care is taken that information is coordinated between different hospital departments, and is 'translated' into easily understood, non-technical language. The press is encouraged to avoid sensational reporting. In the long term, the victim and his family are helped by visiting social workers, and sometimes psychiatrists, to adjust to injuries and express their worries and feelings, especially응 the feeling that neighbours and friends do not want to hear about a trauma that they themselves did not: experience - a feeling well known to British Army psychiatrists among FEPOWs.

The other Israeli paper described the use of social scientists, social workers and psychologists by the Israeli Defence Force, to help civilians caught in 'the front line' $\mathbb{\complement}$ in Galilee, living under frequent shelling during the two years before it was stopped by the war in South Lebanon. They found that the continuous danger was. breaking down social cohesion, in contradiction to the $\vec{\omega}$ traditional belief that societies unite under a common 2 threat. An "every man for himself" attitude was, prevalent, with resentment towards the authorities for not preventing the shelling, and bitterness among? victims against unharmed neighbours. Systematic ${ }_{\vec{\omega}}^{\omega}$ attempts at "team building" by public meetings were tried, with limited success. Negative feelings were aireg, $\overrightarrow{\dot{\omega}}$ and discussed. By providing a central staff and $\bar{\omega}$ information service, the "every man for himself" ethös was to some extent broken down, and feelings $\mathrm{ff}$ isolation and resentment overcome.

In contrast to the two Israeli papers, the other papefs? presented on the socio-economic aspects of disasteqs dealt in very general terms with natural catastrophes ${ }_{i n} \cdot \overrightarrow{0}$ under-developed countries, the 1976 Guatemagaos earthquake, and drought and flood in India. T通: emphasis was on long term planning.

The first afternoon's workshop, "Psychologicin Aspects of Disasters", again was chiefly contributed by Israeli speakers, although Col Levy, Chief Psychiatrist of the Israel Defence Force was unable to present his尺 paper on systematic preparation for intervention in $\overrightarrow{\vec{O}}$ combat reaction. IDF psychiatrists and psychiatric social3 workers described psychological problems following? 'multivictim road accidents' in the IDF, and after the freeing of hostages taken by terrorists in a school in Israel recently. The latter paper concentrated on the paradox that military action by the method of storming the building can cause more damage than the terrorists, $\frac{\vec{\nabla}}{\mathrm{D}}$ with bitterness among the victims. The antidote is full@ explanation and discussion between military and $\vec{F}$ civilians, so that the latter can understand the necessity of military action. The second Israeli paper dealt with $\mathrm{a}$. small scale but common disaster in the IDF, fatal crasheso involving army trucks carrying soldiers, usually on poor mountain roads. The theme of the paper was the dangero of disintegration of morale in the unit involved, because $>$ of ill feeling toward the driver and "survivor guilt"을. among the uninjured - a guilt familiar to British ArmyN psychiatrists after the South Atlantic battles. Follow up of units involved in the accidents found that many uninjured soldiers had become psychologically unfit forc 
further service but this could be prevented with some success by keeping the unit together and at work immediately after the accident. Previously, the soldiers had been sent on extended leave, on the basis that they would recover if given a holiday. In fact, it was during the compassionate leave that they often failed to come to terms with what had happened, because they did not have the opportunity to understand their feelings within their group. The new policy is to delay leave, and hold meetings in which the soldiers can talk to each other, encouraged by psychiatric social workers, about what they feel. The similarity to the management of battleshock is significant - immediate, extended withdrawal from the situation in which a trauma occurs perpetuating the psychological ill effects of trauma. A third Israeli paper, which ended in a heated discussion about freedom of the press, was a description of the role of the press and the medical community in the Jordan West Bank epidemic of "mysterious gas poisoning" recently. This started at an Arab school, in an area where the Arabs felt specially threatened by new Israeli settlements, after an Israeli newspaper had published an article about a new nerve gas and suggested it was in the IDF's possession. The first victims, all girls, claimed to have seen a cloud of gas in school, and developed symptoms such as a feeling of suffocation, limb paralysis and blindness. The Arab doctor of the local hospital was unable to examine them thoroughly because of the crowd of frightened friends who came with the girls to hospital. Because of a shortage of beds, the girls were kept together, and were accessible to the local press. The epidemic spread rapidly to other schools and was sensationally reported in the local newspapers. It was stopped by removal of the girls to distant hospitals, where they immediately recovered. The paper discussed the mechanism of "mass hysteria", and the danger of this in a conflict involving chemical weapons - one of several Israeli papers that recognized the possibility of chemical warfare.

The second day was taken up by an all day workshop on "Education and Training for Disaster Situations". During the first half, Israeli, US and Swedish contributors described their respective training programmes. Surprisingly, the IDF has recently found that newly qualified doctors are often seriously lacking in knowledge and experience in treating victims of trauma. Consequently the Surgeon General of the IDF has drawn up a compulsory curriculum in traumatology for all medical students, which includes experience with the ambulance service, and ends with a disaster exercise, a city devastated by an earthquake, to teach the importance of organization in response to disasters. The first US paper described the US military medical school's curriculum, broadly similar to the Israeli one, the second US paper outlined the first US "International Diploma in Disaster Management" begun in 1982 at the

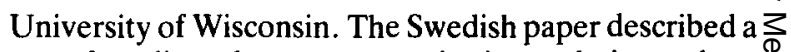
test of cardio-pulmonary resuscitation techniques done $\propto$ without warning on the staff in one major hospital which $ᄋ$ found that only half the doctors and ambulance staff could perform adequately.

The second half of the workshop on training was an $\overrightarrow{\vec{\omega}}$ analysis of decision-making in disaster management, $\vec{\sigma}$ with descriptions of management exercises. Col 등 Ritchie's work at the Operational Research Branch of $\frac{\bar{w}}{\bar{w}}$ the Royal Military College of Science, Shrivenham, was $\vec{D}$ presented by his research assistant. Col Ritchie has 2 developed a three-day computer supported exercise,, "Atlantis", in role playing in positions of responsibility $\overrightarrow{0}$ on a government disaster committee, after a five year study of 16 disasters worldwide. He came to the $\vec{\omega}$ conclusion that more distress arose from administrative failures than from the natural phenomena of disasters. "Atlantis" can be used as part of a course in administration, or on its own as a management training $\vec{\omega}$ exercise. The chief value of it is the use of a computer to integrate the trainee's decisions, and provide feedback $\frac{1}{1}$ on their practicality. The Israeli paper described $\vec{f} \vec{\omega}$ management exercise in a narrower sphere, hospit魹 administration. The US contributor, an anaesthetist focused on that part of decision-making that falls medical staff, triage. He analysed the often neglectes problem of exercises which are usually successful, b $\overrightarrow{b t} \stackrel{\text { D }}{2}$ weaknesses are shown up in real life. His answer wass that clinical decision-making in normal cirumstances is $\vec{\varphi}$ too different from that needed in disasters, specially fơ or hospital as opposed to community staff. Triage disasters during the early stages, when local hospitals a overloaded, involves decisions that would be ruthless and unethical in normal times. He suggested, like $\mathrm{Col}$ Ritchie, that the use of computers in triage exercises was a valuable way of making them more lifelike. Another proposal for efficient triage was a system of 'trauma scores'. Such a system was tested in nine hospitals in Oakland County, Michigan, USA, for four months during 1982. Scoring was done by the emergency team on arriving at the scene of road accidents, again by a doctor or nurse on arrival of the injured in hospital, and finally, after a few weeks, by a hospital consultant,

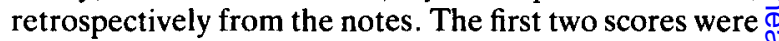
very similar, but the retrospective follow-up showed that a quarter of those scored initially as having minor injuries had needed intensive care, ie were in fact severely injured. Another major difficulty in triage was $\delta$ described by the Director of Emergency Services during 3 the 1983 bushfire disaster in Victoria, Australia. This is 0 the difficulty of sorting out the severely injured from the dazed, or psychologically shocked, when both were unable to give an account of their symptoms. This is the problem faced by military medical staff in distinguishing $\%$ battleshock from physical injury. The Australian $N$ experience was that community staff, specially General $\mathrm{W}_{\mathrm{N}}$ 
Practitioners were better at this kind of triage than hospital staff, being more aware of the often severe effects of psychological trauma.

There were many papers of direct military relevance that I was unable to hear, but could only read the abstracts. These were chiefly concerned with the Israelis' new techniques of prevention and treatment of injuries. Notable among them was a plastic surgeon's account of the IDF success in preventing burns in tank crews during the 1982 war in Lebanon. By strictly enforcing the wearing of fireproof combat suits, the proportion of those burnt who had burns over $10 \%$ of body surface or more was reduced from $79 \%$ to $50 \%$, while those with the severest burns, over $40 \%$ of body surface, was reduced from $29 \%$ to $18 \%$, compared to the 1973 Yom Kippur War. These dramatic figures did not apply to facial burns, the tank crews finding the facial masks unwearable. The development of an acceptable mask is a high priority. An Israeli eye surgeon told of the successful prevention of eye injuries during the 1982 war by visors.
Another series of significant papers presented by $\underset{\Phi}{\overparen{2}}$ Israelis covered peace-time chemical accidents, with the implication that they take the possibility of chemicalo warfare seriously. But only one paper concerned nuclear warfare, presented by a member of 'the Israeli $\Rightarrow$ Association of Physicians for the Prevention of Nuclear $\stackrel{5}{+}$ War', and he dismissed the possibility of efficiento management of such a disaster.

To sum up, the chief message of the contributors $\mathrm{I}_{\alpha}^{\mathrm{\Phi}}$ heard was 'be prepared', and especially be ready for the psychological and social effects of disasters. Disaster plans must be frequently rehearsed and modified, and. exercises can be made more lifelike by an emphasis on $\vec{\omega}$ decision-making, and by the age of computers. Israel is ${ }^{\circ}$ the only "Western" nation in which disasters are almost an everyday occurrence, and has much to teach other $\exists$ nations. I found the conference of great interest, with? many lessons for military psychiatry, and I am grateful $\bar{\omega}$ for the opportunity to visit such a fascinating country as $\grave{c}$ Israel.
Capt A G Paterson, MB, ChB, RAMC. Capt S D Thompson, MB, BS, RAMC. Capt A D Thomson, MB, ChB, RAMC. Maj F B Vella, MB, ChB, DRCOG, RAMC.

\section{Honorary Consultants to the Army}

Professor V M W Drury, OBE, FRCGP, was appointed Honorary Consultant in General Practice to the Army with effect from 16 October 1984.

This is a new appointment - Joint appointment wit Dr J Fry.

\section{ACADEMIC ACHIEVEMENTS}

FRCS Lt Col C G Callow, MB, ChB, DPhysMed, RAMC.

MRCPsych Maj J S McPherson, MRCS, LRCP, DRCOG, RAMC.

Capt K C M Wilson, MB, ChB, RAMC.

MSc Maj P Rasor, MB, BS, RAMC.

MRCGP Maj R L D Jones, MB, ChB, RAMC. Capt P M Mackay, MB, BS, RAMC. 